\title{
Novel molecular imaging platform for monitoring oncological kinases
}

\author{
Shyam Nyati ${ }^{1,4}$, Brian D Ross ${ }^{2,3,4}$, Alnawaz Rehemtulla1,2,3,4 , Mahaveer S Bhojani ${ }^{1,4^{*}}$
}

\begin{abstract}
Recent advances in oncology have lead to identification of a plethora of alterations in signaling pathways that are critical to oncogenesis and propagation of malignancy. Among the biomarkers identified, dysregulated kinases and associated changes in signaling cascade received the lion's share of scientific attention and have been under extensive investigations with goal of targeting them for anti-cancer therapy. Discovery of new drugs is immensely facilitated by molecular imaging technology which enables non-invasive, real time, dynamic imaging and quantification of kinase activity. Here, we review recent development of novel kinase reporters based on conformation dependent complementation of firefly luciferase to monitor kinase activity. Such reporter system provides unique insights into the pharmacokinetics and pharmacodynamics of drugs that modulate kinase signaling and have a huge potential in drug discovery, validation, and drug-target interactions.
\end{abstract}

\section{Introduction}

Cell signaling is a mode of communication by which the intracellular information is conveyed from the site of instigation to the site of action. Recent advances in molecular profiling technologies such as microarrays and proteomics along with synergistic growth in the field of bio-informatics, have actuated our appreciation of signaling changes in patho-physiological conditions and led to identification of unique disease biomarkers [1-5]. For example growth factor such as EGFR or Her-2, may be considered as biomarkers in certain human cancers where they are amplified, overexpressed and/or mutated and immensely alter the downstream signaling [6-12]. Identification of such unique central regulators in the disease signaling has lead to development of targeted molecular drugs $[6,12]$. Although, number of these disease biomarkers have been identified and characterized, the true impact of these understandings will be felt only when applied to diagnosis, staging and treatment of patients. Currently, these innovative developments in understanding the role of biomarkers in human malignancy have minimally ameliorated clinical oncology. This is partly due to the fact that most of the efforts are focused on identifying biomarkers from cancer samples obtained by biopsy of tumors which provide a frozen

\footnotetext{
* Correspondence: mahaveer@umich.edu

'Department of Radiation Oncology, University of Michigan, Ann Arbor MI
} 48109 USA snapshot of biomarkers at the time of sample retrieval and fail to provide any information on the dynamic changes within the malignancy and its milieu [13]. Therefore, concurrent innovations are needed for real time and non-invasive monitoring of biomarker and events they modulate in live cells or organisms [14].

Molecular imaging is a recent area of investigation that attempt to develop suitable probes for noninvasive visual representation of biological processes at the cellular and molecular level in the whole organism and the modalities and instrumentation to support the visualization and quantification of these processes. This is an attempt to bridge the gap between discovery of biomarkers and their deployment in clinic. At present molecular imaging is still largely in the animal experimental phase but promises to bring dramatic change in the way in which a disease is diagnosed, staged and treated. In clinical oncology it will allow oncologists to diagnose cancer at an earlier stage based on molecular characterization, predict the risk of precancerous lesion progression, quantify activities of specific molecules related to tumor growth, invasion and metastasis, select a rational molecular therapy and assess the efficacy of chemo and radio therapeutic agents in real time [15-21]. Over the past several years three different noninvasive imaging technologies have been fine tuned for prime time: (A) optical imaging (bioluminescence and fluorescence imaging) [22-24]; (B) magnetic resonance imaging [MRI] 
[25]; (C) nuclear imaging (e.g single photon emission computed tomography [SPECT] and positron emission tomography [PET]) [26-28]. These have been extensively discussed in a number of reviews and book chapters $[13,14,29-32]$. In this article, we will discuss the recent development in the field of bioluminescent optical imaging for monitoring signaling cascades with special emphasis on luciferase complementation platforms for imaging of kinases.

\section{Bioluminescent optical reporters and complementation assays}

Discovery of reporters that are genetically encoded and generate light such as fluorescent proteins and luciferases in conjunction with the development of instrumentation for real time functional imaging of their activity has offered researchers powerful tools to perform noninvasive studies of dynamic biological process in intact cells and whole organisms. These optical reporter systems have extensively utilized in molecular imaging of signaling pathways mainly because of their efficiency for sequential imaging, operational simplicity, and substantial cost benefits. Bioluminescent firefly luciferase based reporters are widely used for non-invasive, real-time, repetitive imaging both in vitro and in vivo. For monitoring signaling cascade or activity of specific biomarker in vivo, firefly luciferase is the reporter of choice as $30 \%$ of the light generated by firefly luciferase has an emission spectra above $600 \mathrm{~nm}$, a region where the signal attenuation by the absorbing and scattering properties of live mammalian tissue is minimal [33,34]. A major disadvantage of luciferases, like other genetically encoded reporters, is that their use in clinical setting is contingent upon the acceptance of gene therapy protocols for patients. However, in basic research they exhibit a principal advantage in assessing a variety of biological functions including transcriptional and translational regulation, signal transduction, protein-protein interaction, oncogenic and viral transformations, cell migration and trafficking and monitoring tumor burden [35-41] Additionally, a number of modifications have been described for targeting/expressing these reporters in specific organelle, cells or organs by exploiting inducible promoters and regulatory elements [42-46].

Protein complementation assay have garnered a lot of lime light for monitoring protein-protein interaction, kinase and protease activities [47]. Here, the monomeric reporter is split into two separate inactive components in such a way that when these components are brought into close proximity they re-constitute the original reporter activity (Figure 1). Complementation for a number of reporters have been developed for understanding mammalian biology. These include fluorescent proteins (GFP and YFP), bioluminescent enzymes
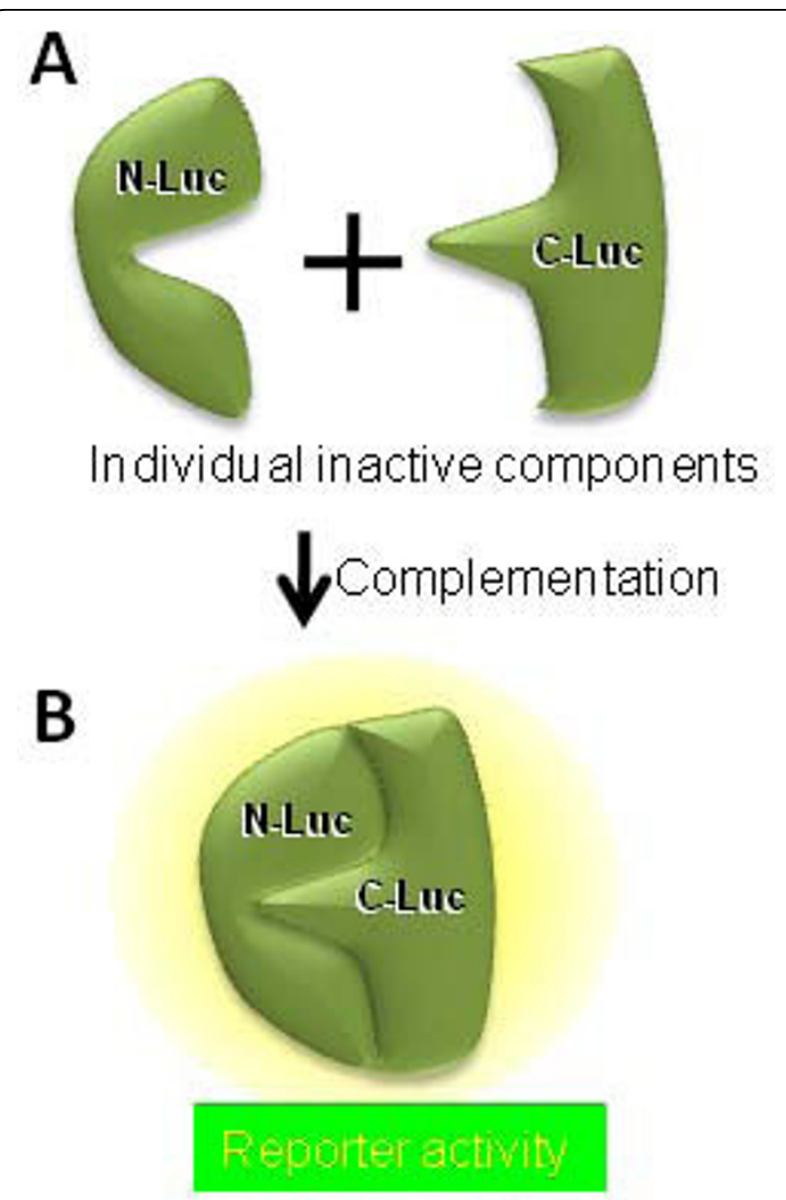

Figure 1 Principle of luciferase complementation based reporter. When luciferase is split to two components (A), each of the units is incapable of generating bioluminescence. However, when the individual components are brought in close proximity, the luciferase enzymatic activity is restored because of intramolecular complementation (B).

(Firefly Luciferase, Renilla Luciferase, Gaussia Luciferase; Figure 1), $\beta$-galactosidase, dihydrofolate reductase (DHFR) and TME1 b-lactamase [48-54]. Luker et al. optimized firefly luciferase protein complementation by screening incremental truncation libraries of $\mathrm{N}$ - and C-terminal fragments of luciferase [50]. They utilized the complementation assay for demonstrating the phosphorylation dependent interaction between human Cdc25C and 14-3-3-e in vitro and FRB-FKBP12 interaction in vivo in real time non-invasively. On similar lines Paulmurugan and Gambhir [55] developed Renilla luciferase complementation assay and monitored in real time the interaction of MyoD and Id. Similarly, Gaussia luciferase complementation assay were developed by Remy and Michnick [53] where they monitored crosstalk of TGFb and insulin signaling. Li et al [56] reported development of luciferase complementation based probes for ligand dependent EGFR dimerization and 
activation. We have utilized the firefly luciferase complementation for monitoring Akt kinase and caspase-3 protease activity [30,57-59].

\section{Imaging of kinases}

Protein kinases are one of the principle regulators of signaling cascades influencing majority of cellular decisions [60-65]. Protein kinases posttranslationally modify a substrate protein by covalent attachment of a phosphate group to a specific amino acid. This phosphorylation of substrate proteins can be mediated by protein Ser/Thr kinases (at serine or threonine residue) or by protein Tyr kinases (at tyrosine residue). Phosphorylation of target residues in proteins results in changes in substrate activity, sub-cellular location or/and interaction with other proteins [30]. These changes mediate a bulk of signaling in normal eukaryotic cells and are very tightly controlled by autoinhibitory and regulatory constraints which act as a safeguard for aberrant kinase activation [62-66]. Dysregulation and mutations in kinase activity have been reported to play a causal role in more than 400 human diseases including as cancer, neurological disorders, rheumatoid arthritis, and psoriasis [66-71]. Although we have met with colossal success in identification of aberrant kinases in a plethora of diseases, the translation of this information to clinic has been much less successful such that majority of these biomarkers remain undrugged. Therefore, fresh impetus is needed in the areas that will allow identification of novel inhibitors for kinase biomarkers. Towards this, we need the molecular imaging modalities that have the potential to be adapted for high through put screening of inhibitor libraries.

We have recently developed a luciferase complementation based kinase imaging platform that allows quantitative, real time, non-invasive imaging of kinase activity (Figure 1) and is easily amenable for high throughput screening of new drugs $[30,57,58]$. We have utilized this technology to monitor Akt, one of the best characterized serine threonine kinases that is involved in tumor initiation, progression and resistance to cancer treatment and is a central signaling hub wherein many upstream oncogenic stimuli such as growth factor signaling and cytokine cascades converge [72]. This recombinant bioluminescent $\underline{\text { Akt }}$ reporter, (BAR) was constructed by fusion of an Akt consensus substrate peptide and phospho-amino acid binding domain (FHA2) which were flanked by the amino- (N-Luc) and carboxyl- (C-Luc) terminal domains of the firefly luciferase reporter molecule (figure 2). In the presence of Akt kinase activity, phosphorylation of the Akt consensus substrate sequences within the reporter results in its

A

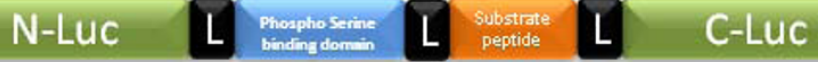

B
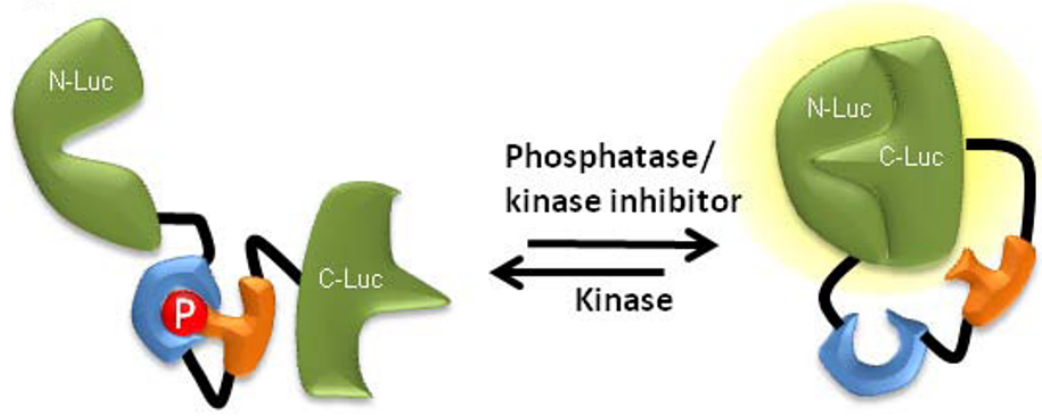

Reporter OFF

Kinase ON

Reporter ON

Kinase OFF

Figure 2 The domain structure and mechanism of action of a kinase reporter. (A) N-LuC (amino acids 2-416) and C-LuC (amino acids 398550) are the amino- and carboxy-terminal domains of firefly luciferase that are fused to the appropriate ends of the reporter. The peptide domain constitutes a kinase substrate sequence with a flexible linker (L) containing of GlyGlySerGlyGly on either side. Yeast Rad52p FHA2 phospho-Ser/Thr binding domain (residues 420-582) attached to the amino-terminal of substrate peptide domain. (B) The proposed mechanism of action for the split luciferase based kinase reporter involves kinase dependent phosphorylation of the target peptide which results in its interaction with the FHA2 domain. In this form the reporter has minimal bioluminescence activity. In the absence of kinase activity, association of the N-LuC and C-Luc domains restores bioluminescence activity. 
interaction with the FHA2 domain, thus stearically preventing reconstitution of a functional luciferase reporter molecule. In the absence of Akt kinase activity, release of this stearic constraint allows reconstitution of the luciferase reporter molecule whose activity can be detected non-invasively by bioluminescent imaging (BLI). The inhibition of Akt activity using an Akt inhibitor, API2 and a PI-3K inhibitor, perifosine resulted in an increase of bioluminescence activity in a time- and dose-dependent manner (figure 3), which indicated that BAR provides a surrogate for Akt activity in terms of quantity and dynamics $[57,58]$. BAR was also used to study upstream signaling events of Akt. For example, stimulation of EGFR could be evaluated using Akt activity as a surrogate and monitored by bioluminescent imaging [57]. The use of an EGFR inhibitor, erlotinib in the erlotinib-sensitive and -resistant cell lines resulted in differential activation of the BAR reporter. In summary, BAR allows imaging of signaling leading to activation/ inactivation of Akt in a quantitative, dynamic and noninvasive manner and that this kinase imaging platform may be adapted for other kinases.

In vivo imaging in animals is a significant advantage of bioluminescent kinase which allows for an enhanced understanding of pharmacokinetics and bioavailability of specific drugs. For example, at $40 \mathrm{mg} / \mathrm{kg} \mathrm{API}-2$ treatment, peak inhibition was detected at 12 hours and inhibitory levels of the compound were detected for up to 24 hours (high bioluminescence) but decreased thereafter (figure 3B). In contrast, when $20 \mathrm{mg} / \mathrm{kg}$ was delivered, although peak inhibition was detected at 12 hours, a decrease in reporter activity was measured in subsequent measurements [57]. Unlike API-2 for which published pharmacokinetics data are not available, the pharmacokinetics of perifosine has been extensively studied. Published data demonstrated that high plasma concentrations of the drug could be detected for as long as seven days post treatment $[73,74]$. The high levels of Akt inhibitory activity for three days detected with noninvasive BAR supports the above observation (figure 3C). Further, Perifosine induced a 12 fold induction in BAR bioluminescence activity while API-2 showed only 4-fold. This difference may be reflective of their bioavailability at the tumor site. Such studies establish an important role for bioluminescent kinase imaging platform in detection of in vivo drug-target interaction.

A major utility of bioluminescent kinase reporter is for high throughput screening of a library of inhibitors. Such cell based assays provide a major advantage in that only compounds that interact with the target in the correct cellular compartment and under normal cellular physiological conditions of that compartment $(\mathrm{pH}$, concentrations of specific ions etc.) would be identified. In contrast to other cell based reporter screens, which are fraught with false positives, the kinase reporter described here is a "gain of function assay" wherein the inhibition of kinase activity results in an increase in bioluminescence. For example, compounds that kill cells (and thus result in a loss of signal) or those that inhibit luciferase activity may show up as false positives in typical luciferase/fluorescent/enzyme based assays. However, specific inhibition of reporters like BAR result in an

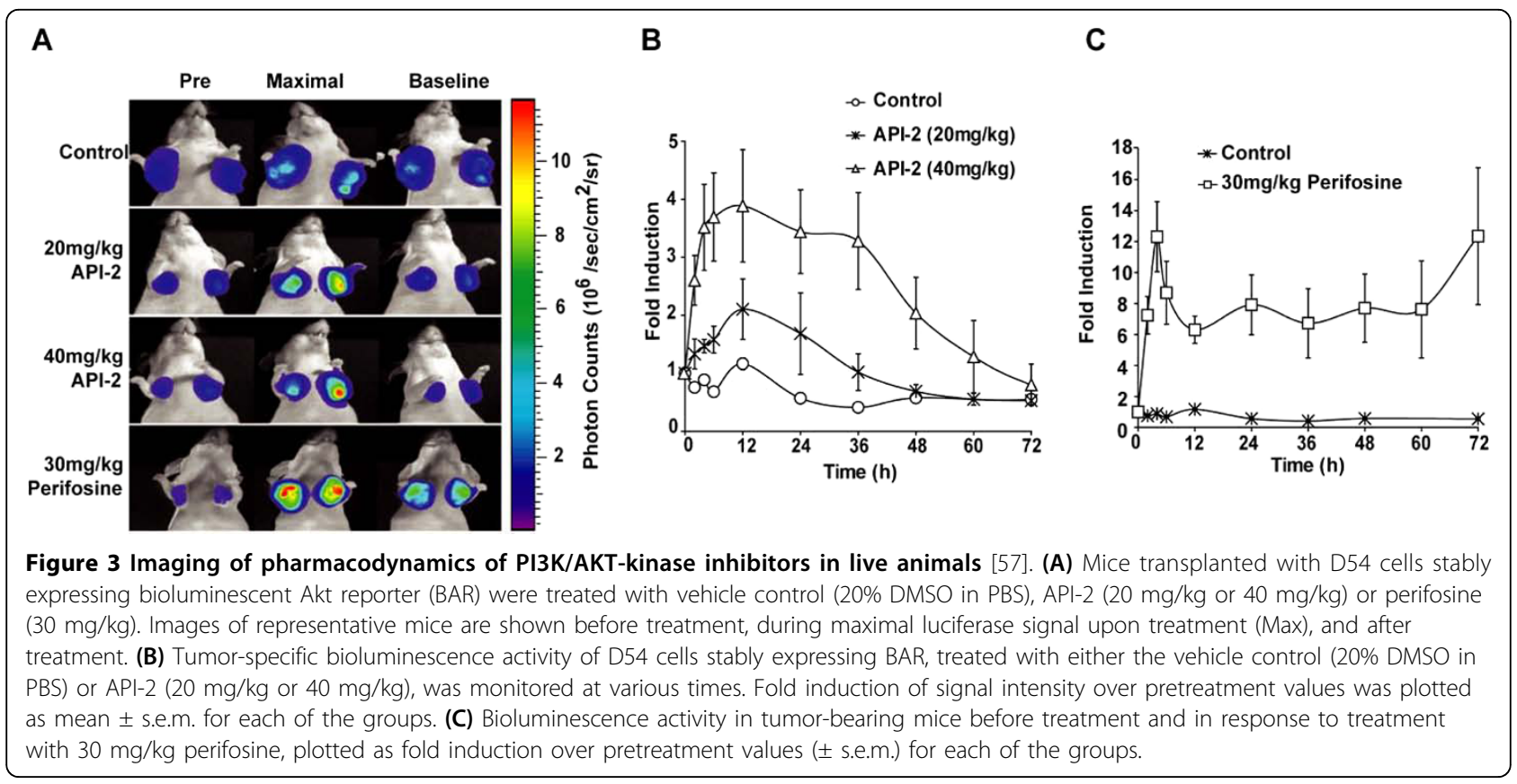


increase in bioluminescence activity and thus non-specific cytotoxic agents are eliminated. Such carefully designed screening methodology will enable us to narrow down the number of positive compounds to a smaller group of "true positives".

Optimum activity and specificity of a kinase is dependent upon its subcellular localization. For example, Akt is recruited to the plasma membrane by PI-3 kinasegenerated D3-phosphorylated phosphoinositides which bind to the Akt $\mathrm{PH}$ domain and induce the translocation $[75,76]$. At the cell membrane, phosphoinositidedependent kinase-1, co-localizes and phosphorylates within the activation loop of Akt $[75,76]$. Therefore, a membrane targeted reporter for Akt activity is more likely to have higher activity. Indeed, the sensitivity of MyrPalm-BAR reporter was more than twice as much when compared with BAR alone in reporting Akt signaling [30]. Thus, utilization of subcellular information of kinases may optimize the kinase reporters and therefore must be employed for reporter construction.

As discussed above, the BAR can be adapted for other protein kinases including receptor or non-receptor Tyr and Ser/Thr kinases by using a suitable substrate and a specific phospho-amino acid binding protein domain. We have successfully adapted this platform for monitoring GSK $3 \beta / C K 1 \alpha$ kinase activities using a $\beta$-catenin substrate sequence [77]. Towards a comprehensive understanding of oncological signaling and accelerating the drug discovery process, we are currently developing imaging tools for several high priority oncological targets such as EGFR, Her2, c-Met, Ras-Raf-MEK-ERK (MAPK), mTor, and TGF $\beta$ receptor. Further, to aid in identifying the target phosphorylation site, there are a number of resources and methodologies described in literature [78-88] and on the web such as http://www. kinasenet.ca, http://www.phosphosite.org, http://www. kinase.com. Experimentally verified phosphorylation sites are available at http://phospho.elm.eu.org and for prediction of phosphorylation site http://www.cbs.dtu. $\mathrm{dk} /$ services/NetPhos/ or http://scansite.mit.edu may be useful.

In summary, molecular imaging reporters for kinases provide a unique opportunity to monitor cellular pathways both in vitro and in vivo. This greatly facilitates the real time visualization of the aberrant oncological signaling and will play an important role in monitoring therapeutic outcome, drug-target validation as well as identification of next generation of drugs.

\section{Acknowledgements}

This work was supported by the US National Institutes of Health research grants R01CA129623 (AR), R21CA131859 (AR), P01CA085878 (BDR),

P50CA093990 (BDR) and by developmental project to MSB by the National
Institute of Health through University of Michigan's Head and Neck SPORE Grant (5 P50 CADE97248).

\section{Author details}

'Department of Radiation Oncology, University of Michigan, Ann Arbor Ml 48109 USA. ² Department of Radiology, University of Michigan, Ann Arbor Ml 48109 USA. ${ }^{3}$ Department of Biological Chemistry, University of Michigan, Ann Arbor Ml 48109 USA. ${ }^{4}$ Center for Molecular Imaging, University of Michigan, Ann Arbor Ml 48109 USA.

\section{Author's contributions}

SN and MSB wrote the review and made the figures. AR and BDR revised the manuscript.

\section{Competing interests}

The authors declare that they have no competing interests.

Received: 24 May 2010 Accepted: 8 July 2010 Published: 8 July 2010

\section{References}

1. Sara $\mathrm{H}$, Kallioniemi $\mathrm{O}$, Nees $\mathrm{M}$ : A decade of cancer gene profiling: from molecular portraits to molecular function. Methods in molecular biology (Clifton, NJ) 576:61-87.

2. Camp RL, Neumeister V, Rimm DL: A decade of tissue microarrays: progress in the discovery and validation of cancer biomarkers. $J$ Clin Oncol 2008, 26(34):5630-5637.

3. van de Rijn M, Gilks CB: Applications of microarrays to histopathology. Histopathology 2004, 44(2):97-108.

4. Virtanen C, Woodgett J: Clinical uses of microarrays in cancer research. Methods in molecular medicine 2008, 141:87-113.

5. Sotiriou C, Piccart MJ: Taking gene-expression profiling to the clinic: when will molecular signatures become relevant to patient care? Nat Rev Cancer 2007, 7(7):545-553.

6. Gazdar AF: Epidermal growth factor receptor inhibition in lung cancer: the evolving role of individualized therapy. Cancer Metastasis Rev 2010, 29(1):37-48.

7. Baselga J: The EGFR as a target for anticancer therapy-focus on cetuximab. Eur J Cancer 2001, 37(Suppl 4):S16-22.

8. Grunwald V, Hidalgo M: Developing inhibitors of the epidermal growth factor receptor for cancer treatment. J Natl Cancer Inst 2003, 95(12):851-867.

9. Haas-Kogan DA, Prados MD, Tihan T, Eberhard DA, Jelluma N, Arvold ND, Baumber R, Lamborn KR, Kapadia A, Malec M, et al: Epidermal growth factor receptor, protein kinase B/Akt, and glioma response to erlotinib. J Natl Cancer Inst 2005, 97(12):880-887.

10. Giaccone G: HER1/EGFR-targeted agents: predicting the future for patients with unpredictable outcomes to therapy. Ann Oncol 2005, 16(4):538-548.

11. Paez JG, Janne PA, Lee JC, Tracy S, Greulich H, Gabriel S, Herman P, Kaye FJ, Lindeman $\mathrm{N}$, Boggon $\mathrm{T}$, et al: EGFR mutations in lung cancer: correlation with clinical response to gefitinib therapy. Science (New York, NY) 2004, 304(5676):1497-1500.

12. Ross JS, Slodkowska EA, Symmans WF, Pusztai L, Ravdin PM, Hortobagyi GN: The HER-2 receptor and breast cancer: ten years of targeted anti-HER-2 therapy and personalized medicine. Oncologist 2009, 14(4):320-368.

13. Weissleder R, D RB, Rehemtulla A, Gambhir SS: Molecular Imaging, Principles and Practice. Shelton, Connecticut, USA: People's Medical Publishing House-USA 2010.

14. Bhojani MS, Ross BD, Rehemtulla A: Imaging of signaling pathways. Molecular Imaging, Priniciples and Practice People's Medical Publishing House-USA, Shelton, CT, USAWeissleder R, D RB, Rehemtulla A, Gambhir SS 2010, 829-841.

15. Weissleder R, Ntziachristos V: Shedding light onto live molecular targets. Nature medicine 2003, 9(1):123-128.

16. Mahmood U, Weissleder R: Near-infrared optical imaging of proteases in cancer. Mol Cancer Ther 2003, 2(5):489-496.

17. Gelovani Tjuvajev J, Blasberg RG: In vivo imaging of molecular-genetic targets for cancer therapy. Cancer Cell 2003, 3(4):327-332.

18. Chenevert TL, Stegman LD, Taylor JM, Robertson PL, Greenberg HS, Rehemtulla A, Ross BD: Diffusion magnetic resonance imaging: an early 
surrogate marker of therapeutic efficacy in brain tumors. I Nat/ Cancer Inst 2000, 92(24):2029-2036.

19. Moffat BA, Hall DE, Stojanovska J, McConville PJ, Moody JB, Chenevert TL, Rehemtulla A, Ross BD: Diffusion imaging for evaluation of tumor therapies in preclinical animal models. Magma 2004, 17(3-6):249-259.

20. Guccione S, Li KC, Bednarski MD: Molecular imaging and therapy directed at the neovasculature in pathologies. How imaging can be incorporated into vascular-targeted delivery systems to generate active therapeutic agents. IEEE Eng Med Biol Mag 2004, 23(5):50-56.

21. Morgan B, Horsfield MA, Steward WP: The role of imaging in the clinical development of antiangiogenic agents. Hematol Oncol Clin North Am 2004, 18(5):1183-1206, $x$

22. Contag $\mathrm{CH}$, Bachmann $\mathrm{MH}$ : Advances in in vivo bioluminescence imaging of gene expression. Annu Rev Biomed Eng 2002, 4:235-260.

23. Bremer C, Ntziachristos $V$, Weissleder R: Optical-based molecular imaging: contrast agents and potential medical applications. Eur Radiol 2003, 13(2):231-243.

24. Bhaumik S, Gambhir SS: Optical imaging of Renilla luciferase reporter gene expression in living mice. Proceedings of the National Academy of Sciences of the United States of America 2002, 99(1):377-382.

25. Ross BD, Chenevert TL, Rehemtulla A: Magnetic resonance imaging in cancer research. Eur J Cancer 2002, 38(16):2147-2156.

26. Blasberg R: PET imaging of gene expression. Eur I Cancer 2002, 38(16):2137-2146.

27. Blasberg RG, Gelovani J: Molecular-genetic imaging: a nuclear medicinebased perspective. Mol Imaging 2002, 1(3):280-300.

28. Alavi A, Lakhani P, Mavi A, Kung JW, Zhuang H: PET: a revolution in medical imaging. Radiol Clin North Am 2004, 42(6):983-1001, vii.

29. Bhojani MS, Laxman B, Ross BD, Rehemtulla A: Molecular Imaging in Cancer. Apoptosis and Cancer Therapy Weinheim: Wiley-VCHDKMaF S 2006, II:37-59.

30. Zhang L, Bhojani MS, Ross BD, Rehemtulla A: Molecular imaging of protein kinases. Cell cycle (Georgetown, Tex) 2008, 7(3):314-317.

31. Gross S, Piwnica-Worms D: Spying on cancer: molecular imaging in vivo with genetically encoded reporters. Cancer Cell 2005, 7(1):5-15.

32. Narula J, Kietselaer B, Hofstra L: Role of molecular imaging in defining and denying death. J Nucl Cardiol 2004, 11(3):349-357.

33. Greer LF, Szalay AA: Imaging of light emission from the expression of luciferases in living cells and organisms: a review. Luminescence 2002, 17(1):43-74

34. Contag CH, Ross BD: It's not just about anatomy: in vivo bioluminescence imaging as an eyepiece into biology. J Magn Reson Imaging 2002, 16(4):378-387.

35. Rehemtulla A, Stegman LD, Cardozo SJ, Gupta S, Hall DE, Contag CH, Ross BD: Rapid and quantitative assessment of cancer treatment response using in vivo bioluminescence imaging. Neoplasia (New York, NY) 2000, 2(6):491-495.

36. Ciana P, Raviscioni M, Mussi P, Vegeto E, Que I, Parker MG, Lowik C, Maggi A: In vivo imaging of transcriptionally active estrogen receptors. Nature medicine 2003, 9(1):82-86.

37. Carlsen H, Moskaug JO, Fromm SH, Blomhoff R: In vivo imaging of NFkappa B activity. J Immunol 2002, 168(3):1441-1446.

38. Doubrovin M, Ponomarev V, Beresten T, Balatoni J, Bornmann W, Finn R, Humm J, Larson S, Sadelain M, Blasberg R, et al: Imaging transcriptional regulation of p53-dependent genes with positron emission tomography in vivo. Proceedings of the National Academy of Sciences of the United States of America 2001, 98(16):9300-9305.

39. Rehemtulla A, Taneja N, Ross BD: Bioluminescence detection of cells having stabilized p53 in response to a genotoxic event. Mol Imaging 2004, 3(1):63-68,

40. Laxman B, Hall DE, Bhojani MS, Hamstra DA, Chenevert TL, Ross BD, Rehemtulla A: Noninvasive real-time imaging of apoptosis. Proceedings of the National Academy of Sciences of the United States of America 2002, 99(26):16551-16555.

41. Luker GD, Sharma V, Pica CM, Prior JL, Li W, Piwnica-Worms D: Molecular imaging of protein-protein interactions: controlled expression of p53 and large T-antigen fusion proteins in vivo. Cancer research 2003, 63(8):1780-1788

42. Papadakis ED, Nicklin SA, Baker AH, White SJ: Promoters and control elements: Designing expression cassettes for gene therapy. Current Gene Therapy 2004, 4(1):89-113.
43. Ray P, De A, Min JJ, Tsien RY, Gambhir SS: Imaging tri-fusion multimodality reporter gene expression in living subjects. Cancer research 2004, 64(4):1323-1330

44. Sadeghi $H$, Hitt MA: Transcriptionally targeted adenovirus vectors. Current Gene Therapy 2005, 5(4):411-427.

45. Jaffer $F A$, Tung $C H$, Gerszten RE, Weissleder R: In vivo Imaging of thrombin activity in experimental thrombi with thrombin-sensitive near-infrared molecular probe. Arteriosclerosis Thrombosis and Vascular Biology 2002, 22(11):1929-1935.

46. Livet J, Weissman TA, Kang HN, Draft RW, Lu J, Bennis RA, Sanes JR, Lichtman JW: Transgenic strategies for combinatorial expression of fluorescent proteins in the nervous system. Nature 2007, 450(7166):56.

47. Fields S, Song O: A novel genetic system to detect protein-protein interactions. Nature 1989, 340(6230):245-246.

48. Hu CD, Chinenov Y, Kerppola TK: Visualization of interactions among bZIP and Rel family proteins in living cells using bimolecular fluorescence complementation. Mol Cell 2002, 9(4):789-798.

49. Luker GD, Sharma V, Pica CM, Dahlheimer JL, Li W, Ochesky J, Ryan CE, Piwnica-Worms H, Piwnica-Worms D: Noninvasive imaging of proteinprotein interactions in living animals. Proceedings of the National Academy of Sciences of the United States of America 2002, 99(10):6961-6966.

50. Luker KE, Piwnica-Worms D: Optimizing luciferase protein fragment complementation for bioluminescent imaging of protein-protein interactions in live cells and animals. Methods in enzymology 2004 385:349-360.

51. Galarneau A, Primeau M, Trudeau LE, Michnick SW: Beta-lactamase protein fragment complementation assays as in vivo and in vitro sensors of protein protein interactions. Nature biotechnology 2002, 20(6):619-622.

52. Michnick SW, Ear PH, Manderson EN, Remy I, Stefan E: Universal strategies in research and drug discovery based on protein-fragment complementation assays. Nature reviews 2007, 6(7):569-582.

53. Remy I, Michnick SW: A highly sensitive protein-protein interaction assay based on Gaussia luciferase. Nat Methods 2006, 3(12):977-979.

54. Remy I, Michnick SW: Application of protein-fragment complementation assays in cell biology. Biotechniques 2007, 42(2):137, 139, 141 passim.

55. Paulmurugan R, Gambhir SS: Monitoring protein-protein interactions using split synthetic renilla luciferase protein-fragment-assisted complementation. Anal Chem 2003, 75(7):1584-1589.

56. Li WR, Li F, Huang Q, Frederick B, Bao SD, Li CY: Noninvasive imaging and quantification of epidermal growth factor receptor kinase activation in vivo. Cancer research 2008, 68(13):4990-4997.

57. Zhang L, Lee KC, Bhojani MS, Khan AP, Shilman A, Holland EC, Ross BD, Rehemtulla A: Molecular imaging of Akt kinase activity. Nature medicine 2007, 13(9):1114-1119.

58. Zhang L, Bhojani MS, Ross BD, Rehemtulla A: Enhancing Akt imaging through targeted reporter expression. Mol Imaging 2008, 7(4):168-174.

59. Coppola JM, Ross BD, Rehemtulla A: Noninvasive imaging of apoptosis and its application in cancer therapeutics. Clin Cancer Res 2008, 14(8):2492-2501.

60. Manning G, Plowman GD, Hunter T, Sudarsanam S: Evolution of protein kinase signaling from yeast to man. Trends in biochemical sciences 2002, 27(10):514-520.

61. Manning G, Whyte DB, Martinez R, Hunter T, Sudarsanam S: The protein kinase complement of the human genome. Science (New York, NY) 2002, 298(5600):1912-1934

62. Edelman AM, Blumenthal DK, Krebs EG: Protein serine/threonine kinases. Annual review of biochemistry 1987, 56:567-613.

63. Hubbard SR, Till JH: Protein tyrosine kinase structure and function. Annual review of biochemistry 2000, 69:373-398.

64. Hunter T, Cooper JA: Protein-tyrosine kinases. Annual review of biochemistry 1985, 54:897-930

65. Tsygankov AY: Non-receptor protein tyrosine kinases. Front Biosci 2003, 8 s595-635.

66. Blume-Jensen P, Hunter T: Oncogenic kinase signalling. Nature 2001, 411(6835):355-365.

67. Ben-Bassat H: Biological activity of tyrosine kinase inhibitors: novel agents for psoriasis therapy. Curr Opin Investig Drugs 2001, 2(11):1539-1545.

68. Blease K: Targeting kinases in asthma. Expert opinion on investigational drugs 2005, 14(10):1213-1220. 
69. Kumar R, Singh VP, Baker KM: Kinase inhibitors for cardiovascular disease. J Mol Cell Cardiol 2007, 42(1):1-11.

70. Mueller BK, Mack $H$, Teusch N: Rho kinase, a promising drug target for neurological disorders. Nature reviews 2005, 4(5):387-398.

71. Westra J, Limburg PC: p38 mitogen-activated protein kinase (MAPK) in rheumatoid arthritis. Mini Rev Med Chem 2006, 6(8):867-874.

72. Manning BD, Cantley LC: AKT/PKB signaling: navigating downstream. Cell 2007, 129(7):1261-1274.

73. Bailey HH, Mahoney MR, Ettinger DS, Maples WJ, Fracasso PM, Traynor AM, Erlichman C, Okuno SH: Phase II study of daily oral perifosine in patients with advanced soft tissue sarcoma. Cancer 2006, 107(10):2462-2467.

74. Vink SR, Schellens JH, Beijnen JH, Sindermann H, Engel J, Dubbelman R, Moppi G, Hillebrand MJ, Bartelink H, Verheij M: Phase I and pharmacokinetic study of combined treatment with perifosine and radiation in patients with advanced solid tumours. Radiother Oncol 2006, 80(2):207-213.

75. Chan TO, Rittenhouse SE, Tsichlis PN: AKT/PKB and other D3 phosphoinositide-regulated kinases: kinase activation by phosphoinositide-dependent phosphorylation. Annual review of biochemistry 1999, 68:965-1014.

76. Cantley LC: The phosphoinositide 3-kinase pathway. Science (New York, NY) 2002, 296(5573):1655-1657.

77. Nyati S, Ranga R, Ross BD, Rehemtulla A, MS B: Molecular Imaging of GSK3 $\beta$ and CK1 $\alpha$ kinases. Analytical Biochemistry 2010.

78. Cohen P, Knebel A: KESTREL: a powerful method for identifying the physiological substrates of protein kinases. The Biochemical journal 2006, 393(Pt 1):1-6.

79. Murray JT, Campbell DG, Peggie M, Mora A, Cohen P: Identification of filamin $C$ as a new physiological substrate of PKBalpha using KESTREL. The Biochemical journal 2004, 384(Pt 3):489-494.

80. Peng C, Knebel A, Morrice NA, Li X, Barringer K, Li J, Jakes S, Werneburg B, Wang L: Pim kinase substrate identification and specificity. Journal of biochemistry 2007, 141(3):353-362.

81. Huang HD, Lee TY, Tzeng SW, Horng JT: KinasePhos: a web tool for identifying protein kinase-specific phosphorylation sites. Nucleic acids research 2005, , 33 Web Server: W226-229.

82. Senawongse P, Dalby AR, Yang ZR: Predicting the phosphorylation sites using hidden Markov models and machine learning methods. Journal of chemical information and modeling 2005, 45(4):1147-1152.

83. Wong YH, Lee TY, Liang HK, Huang CM, Wang TY, Yang YH, Chu CH, Huang HD, Ko MT, Hwang JK: KinasePhos 2.0: a web server for identifying protein kinase-specific phosphorylation sites based on sequences and coupling patterns. Nucleic acids research 2007, , 35 Web Server: W588-594.

84. Niedner RH, Buzko OV, Haste NM, Taylor A, Gribskov M, Taylor SS: Protein kinase resource: an integrated environment for phosphorylation research. Proteins 2006, 63(1):78-86.

85. Petretti $C$, Prigent $C$ : The Protein Kinase Resource: everything you always wanted to know about protein kinases but were afraid to ask. Biology of the cell/under the auspices of the European Cell Biology Organization 2005, 97(2):113-118.

86. Smith CM: The protein kinase resource and other bioinformation resources. Progress in biophysics and molecular biology 1999, 71(3-4):525-533.

87. Smith CM, Shindyalov IN, Veretnik S, Gribskov M, Taylor SS, Ten Eyck LF, Bourne PE: The protein kinase resource. Trends in biochemical sciences 1997, 22(11):444-446.

88. MacDonald JA, Mackey AJ, Pearson WR, Haystead TA: A strategy for the rapid identification of phosphorylation sites in the phosphoproteome. Mol Cell Proteomics 2002, 1(4):314-322.

doi:10.1186/1475-2867-10-23

Cite this article as: Nyati et al:: Novel molecular imaging platform for monitoring oncological kinases. Cancer Cell International 2010 10:23.

\section{Submit your next manuscript to BioMed Central and take full advantage of:}

- Convenient online submission

- Thorough peer review

- No space constraints or color figure charges

- Immediate publication on acceptance

- Inclusion in PubMed, CAS, Scopus and Google Scholar

- Research which is freely available for redistribution

Submit your manuscript at www.biomedcentral.com/submit
Biomed Central 